\title{
Colorectal Cancer Incidence and Mortality Trends and Analysis of Risk Factors in China from 2005 to 2015
}

\author{
Chao Sun $\mathbb{D}^{1,2, *}$ \\ Yan Liu ${ }^{1,2, *}$ \\ Yiman Huang ${ }^{3}$ \\ Bang $\mathrm{Li}^{2}$ \\ Weiqing Rang'
}

'Hunan Key Laboratory of Typical Environmental Pollution and Health Hazards, School of Public Health, Hengyang Medical School, University of South China, Hengyang, Hunan, People's Republic of China; ${ }^{2}$ School of Public Health, Wuhan University, Wuhan, Hubei, People's Republic of China; ${ }^{3}$ Department of Public Health, School of Population Medicine and Public Health, Chinese Academy of Medical Sciences and Peking Union Medical College, Beijing, People's Republic of China

*These authors contributed equally to this work
Correspondence: Weiqing Rang Hunan Key Laboratory of Typical Environmental Pollution and Health Hazards, School of Public Health, Hengyang Medical School, University of South China, The 28th of Changsheng

Road, Hengyang, Hunan, People's

Republic of China

Email rwqktz2018@I26.com
Purpose: This study aimed to analyze incidence and mortality trends and risk factors of colorectal cancer (CRC) in China during 2005-2015.

Materials and Methods: Patient cases were extracted from the Chinese Cancer Registry Annual Report. Joinpoint regression and Poisson regression were applied to analyze incidence and mortality trends and risk factors of CRC. Age-period-cohort model was used to evaluate the age, period and cohort effects on CRC.

Results: The standardized incidence and mortality rate of $\mathrm{CRC}$ in China showed a decreasing trend during 2005-2015. The incidence in men (APC $=-1.22 \%, P<0.05$ ) decreased from 2005 to 2015 and decreased in women ( $\mathrm{APC}=-3.55 \%, \mathrm{P}<0.05$ ) from 2005 to 2013, then increased during 2013-2015 (APC $=18.77 \%, \mathrm{P}<0.05$ ). The incidence and mortality in urban areas were higher than those in rural (The incidence in urban: $\mathrm{APC}=$ $-0.97 \%, \mathrm{P}<0.05$; rural: $\mathrm{APC}=1.94 \%, \mathrm{P}<0.05$; the mortality in urban: $\mathrm{APC}=-0.67 \%$, $\mathrm{P}<0.05$; rural: APC $=0.29 \%$ ). For age-specific rates, the incidence begins to increase significantly at $40-45$ age group and reached a peak at 75 ; the mortality increased significantly at 45-50. The age effect increased with age in general. The 1920 birth cohort had the highest risk of colorectal cancer incidence and death. Poisson regression showed region, gender and age were independent risk factors of CRC.

Conclusion: The age-adjusted standardized incidence rate (ASIR) and age-adjusted standardized mortality rate (ASMR) of CRC in China during 2005-2015 were decreasing. A great concern on men, rural areas and people aged over 75 should be aroused to prevent colorectal cancer.

Keywords: colorectal cancer, incidence, mortality, joinpoint regression, poisson regression, age-period-cohort model

\section{Introduction}

Colorectal cancer (CRC) is one of the most common malignant tumors in the world, and the incidence and mortality of colorectal cancer has gradually risen in recent years. The incidence of CRC in younger adults ( $<50$ years old) is rising worldwide, which has been at a rate of $1 \%$ per annum since mid-1980s and nearly 2 times as high as that in older populations. ${ }^{1}$ This trend raised clinical concerns that younger adults may have more advanced disease leading to poorer prognosis compared to their older cohort due to lack of screening. ${ }^{2}$ The distribution of CRC is significantly different in regions all over the world. It mainly occurs in Australia, Europe and North America. In general, the incidence in developed countries or regions is about 
three times higher than that in less developed areas. ${ }^{3}$ However, it is increasing in Asia, which cannot be ignored. $^{4-6}$

In China, the incidence and mortality of CRC showed an increasing trend year by year. According to data from Chinese Cancer Registration in 2014, both the incidence and mortality of CRC were the highest in the eastern region, followed by the central region, and the lowest in the western region. The mortality rate of colorectal cancer in urban areas of China increased significantly from 2002 to 2008 and decreased from 2008 to 2015, while that in rural areas was increasing. ${ }^{7}$ Studies have shown that family history of CRC and a history of inflammatory bowel disease, liver disease, non-CRC cancer and unhealthy diet habits are significant risk factors for CRC. Specifically, processed meats, animal fats and cholesterol have a positive stimulation on colorectal cancer, while calcium foods, general vegetable, fruit, fiber consumption, soy products, selenium, vitamin and minerals play a protective role. Early colonoscopy may also reduce the odds of CRC. ${ }^{8-10}$

Although some descriptive studies on CRC have been conducted, few of them analyzed the long-term trend and applied the age-period-cohort model (APC model). This study analyzed the incidence and death trends of colorectal cancer from 2005 to 2015, calculated the annual percentage change (APC) and the average annual percentage change (AAPC) with Joinpoint software, which could avoid the imperfection of traditional linear trends. In our study, Poisson regression was applied due to its advantage of describing the occurrence or death of malignant tumor with minimal probability. Additionally, APC model can independently evaluate age, period and cohort effects, thus providing scientific references, prevention and control measures for future research.

\section{Materials and Methods \\ Data Sources}

The data were obtained from the Chinese Cancer Registry Annual Report, annually published by The National Cancer Center of China in charge of the collection, examination and publication of national cancer registration. The incidence and mortality of different age, gender and region were extracted from the report, of which reliability, completeness and validity have been evaluated.

\section{Statistical Analysis}

Joinpoint Regression Model

The joinpoint regression model is often used to analyze the linear characteristics of disease incidence or mortality over time, the inflection point generated in the linear trend, the annual APC and AAPC before and after the inflection point, whether the changes in different periods are statistically significant, and explore possible causes. ${ }^{11,12}$ This study calculated the incidence and mortality of colorectal cancer in China from 2005 to 2015, as well as APC and AAPC in different observation periods, and explored possible causes. The computational formula can be expressed as:

$$
\begin{gathered}
\mathrm{APC}=\left(\mathrm{e}^{\beta}-1\right) \times 100 \% \\
\mathrm{AAPC}=\left(e^{\frac{\sum \omega i b i}{\sum \omega i}}-1\right) \times 100 \%
\end{gathered}
$$

In the linear model $\mathrm{y}=\mu+\beta \mathrm{x}+\varepsilon, \beta$ is the regression coefficient, $y$ represents the logarithm of disease incidence or mortality, $\mathrm{x}$ denotes the independent variable, $\mu$ and $\varepsilon$ refer to the intercept and random error, respectively. $\omega_{i}$ represents the length of each segment in the year range, bi was the slope coefficient.

\section{Poisson Regression Model}

Poisson regression ${ }^{13}$ is a kind of generalized linear regression based on weighted least square or maximum likelihood method. In the generalized linear model, the dependent variable $\mathrm{Y}$ obeys the Poisson distribution, the parameter is $\lambda$, and the influencing factors are $\mathrm{x}_{1}, \mathrm{x}_{2}, \ldots$, $\mathrm{x}_{\mathrm{m}}$, then:

$$
\log (\lambda)=\beta_{0}+\beta_{1} \mathrm{x}_{1}+\beta_{2} \mathrm{x}_{2}+\beta_{3} \mathrm{x}_{3}+\ldots+\beta_{\mathrm{m}} \mathrm{x}_{\mathrm{m}}
$$

The regression coefficient $\beta_{\mathrm{i}}$ denotes the average change of the incidence and mortality of CRC when one of the independent variables (age, region and sex) changes. Then calculate the odds ratio (OR) and $P$ value to judge whether independent variables are protective or risk factors.

\section{Age-Period-Cohort Model}

APC model ${ }^{11,14}$ can analyze the effect of multiple complex factors on individual groups independently, eliminating the interaction of age, period and cohort effects. The model can be expressed as

$$
\mathrm{Y}=\log (\mathrm{M})=\mu+\alpha \mathrm{X} 1+\beta \mathrm{X} 2+\gamma \mathrm{X} 3+\varepsilon
$$


where $\mathrm{M}$ refers to the incidence and mortality of $\mathrm{CRC}$; $\alpha$, $\beta, \gamma$ refer to the effect coefficient of age, period, cohort; and $\mu, \varepsilon$ refer to the intercept and random error.In this study, patients were classified into 14 age groups (20-, 25-, 30-, 35-, 40-, 45-, 50-, 55-, 60-, 65-, 70-, 75-, 80-, 85-), 3 period groups $(2005,2010,2015)$ and 16 cohort groups (1920-, 1925-, 1930-, 1935-, 1940-, 1945-, 1950-, 1955-, 1960-, 1965-, 1970-, 1975-, 1980-, 1985-, 1990-, 1995-). The $\mathrm{P}$ value and effect coefficients were calculated to evaluate the age, period and cohort effects.

\section{Results}

\section{Specific Standardized Incidence and Mortality Trends by Gender}

Trends in total standardized incidence and mortality of colorectal cancer in China from 2005 to 2015 are shown in Figures 1 and 2 and Table 1. For men, both the incidence $(\mathrm{APC}=-1.22 \%, \mathrm{P}<0.05)$ and mortality $(\mathrm{APC}=-1.19 \%$, $\mathrm{P}<0.05)$ were on the decline. For women, the incidence declined during 2005-2013 ( $\mathrm{APC}=-3.55 \%, \mathrm{P}<0.05)$ and increased in 2013-2015 ( $\mathrm{APC}=18.77 \%, \mathrm{P}<0.05)$. But the mortality of women declined steadily (APC $=-2.36 \%$, $\mathrm{P}<0.05)$. During this period, the incidence and mortality of men were apparently higher than women.

\section{Specific Standardized Incidence and Mortality Trends by Region}

Trends in total standardized incidence and mortality of colorectal cancer in China from 2005 to 2015 were shown in Figures 3 and 4 and Table 2. In urban areas, the incidence and mortality decreased slowly (ASIR: $\mathrm{APC}=-0.97 \%$, $\mathrm{P}<0.05$; ASMR: $\mathrm{APC}=-0.67, \mathrm{P}<0.05)$. However, the incidence in rural areas increased gradually $(\mathrm{APC}=1.94 \%$, $\mathrm{P}<0.05)$ and the urban-rural gap was narrowing. Rural mortality increased slightly.

\section{Specific Incidence and Mortality Trends by Age}

The trend of incidence and mortality by age of colorectal cancer in China from 2005 to 2015 was shown in

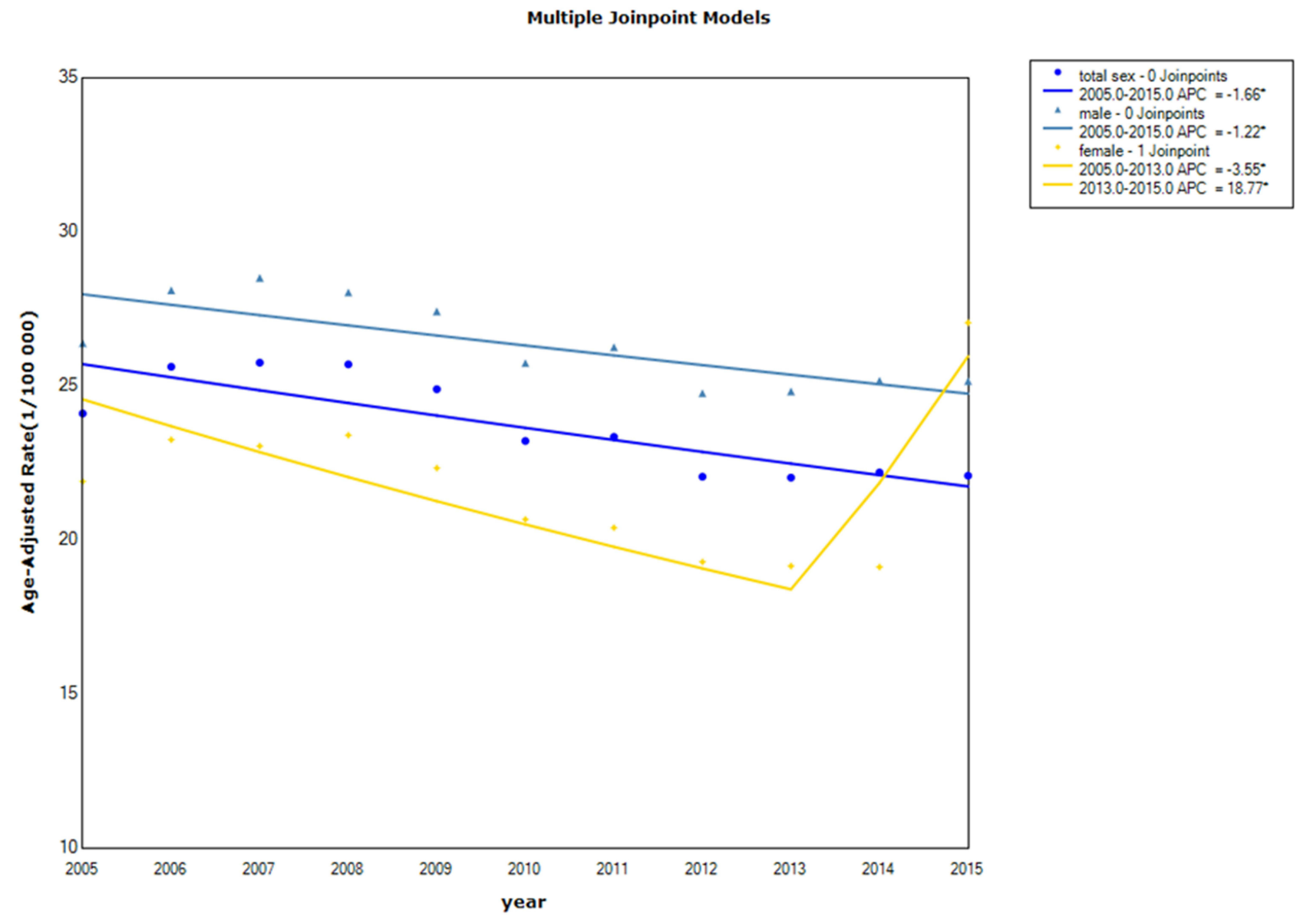

Figure I Trend of male-female standardized incidence of colorectal cancer in China from 2005 to 2015. Note: *Means $\mathrm{P}<0.05$, and the difference is statistically significant. 
Multiple Joinpoint Models
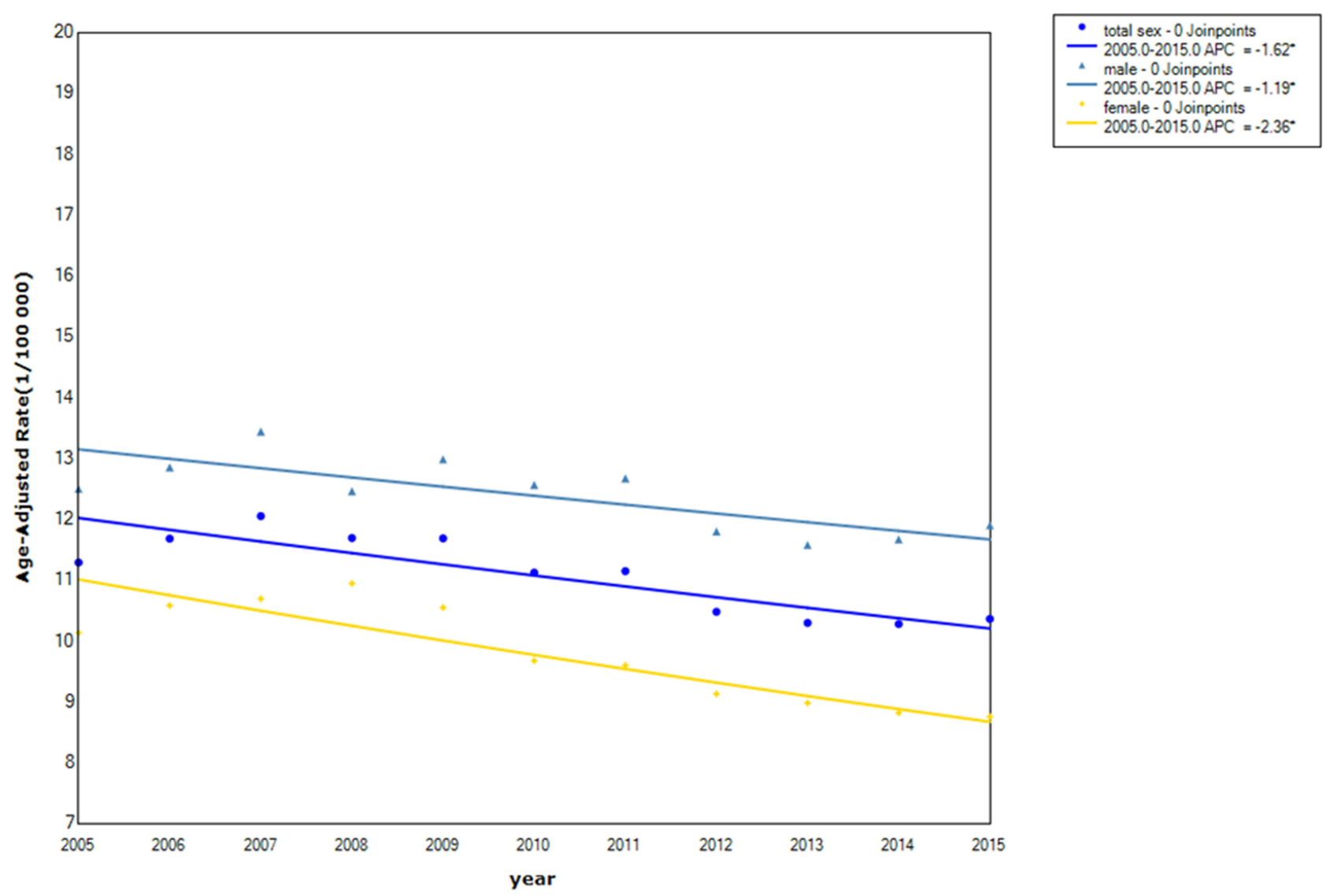

Figure 2 Trend of male-female standardized mortality of colorectal cancer in China from 2005 to 2015.

Note: *Means $\mathrm{P}<0.05$, and the difference is statistically significant.

Figures 5 and 6 . The incidence can be roughly divided into four sections: it depicted a slow rise in age group 045 and increased rapidly in age group 45-60 over the years then rose continuously in age group 60-75. In the 75 group, all the age-specific incidence showed a downward trend except the year 2008 and 2014. Although the incidence of the age group 75 decreased gradually with the increase in age, it was still higher than that in other age groups and the population aged 75 were the high-risk groups of colorectal cancer. With regard to

Table I APC and AAPC of Male-Female Standardized Incidence and Mortality of Colorectal Cancer in China from 2005 to 2015

\begin{tabular}{|c|c|c|c|c|c|c|c|}
\hline \multirow[t]{2}{*}{ Gender } & \multirow[t]{2}{*}{ Year } & \multicolumn{3}{|c|}{ Annual Change } & \multicolumn{3}{|c|}{ Average Annual Change } \\
\hline & & APC $(95 \% \mathrm{CI})$ & $\mathbf{t}$ & $\mathbf{P}$ & AAPC $(95 \% \mathrm{CI})$ & $\mathbf{t}$ & $\mathbf{P}$ \\
\hline \multicolumn{8}{|l|}{ ASIR } \\
\hline All & $2005-2015$ & $-1.66 *(-2.33,-0.99)$ & -5.60 & 0.00 & $-1.66 *(-2.33,-0.99)$ & -5.60 & 0.00 \\
\hline Males & $2005-2015$ & $-1.22 *(-1.87,-0.56)$ & -4.20 & 0.00 & $-1.22 *(-1.87,-0.56)$ & -4.20 & 0.00 \\
\hline Females & $2005-2013$ & $-3.55 *(-5.06,-2.01)$ & -5.61 & 0.00 & $0.55(-1.03,-2.16)$ & 0.68 & 0.50 \\
\hline & $2013-2015$ & $18.77 *(10.04,28.20)$ & 5.51 & 0.00 & & & \\
\hline \multicolumn{8}{|l|}{ ASMR } \\
\hline All & $2005-2015$ & $-1.62 *(-2.22,1.02)$ & -6.09 & 0.00 & $-1.62 *(-2.22,1.02)$ & -6.09 & 0.00 \\
\hline Male & $2005-2015$ & $-1.19 *(-1.87,-0.50)$ & -3.87 & 0.00 & $-1.19 *(-1.87,-0.50)$ & -3.87 & 0.00 \\
\hline Female & $2005-2015$ & $-2.36^{*}(-3.05,1.66)$ & -7.60 & 0.00 & $-2.36 *(-3.05,1.66)$ & -7.60 & 0.00 \\
\hline
\end{tabular}

Note: *Means $\mathrm{P}<0.05$, and the difference is statistically significant.

Abbreviations: ASIR, age-standardized incidence rate; ASMR, age-standardized mortality rate. 


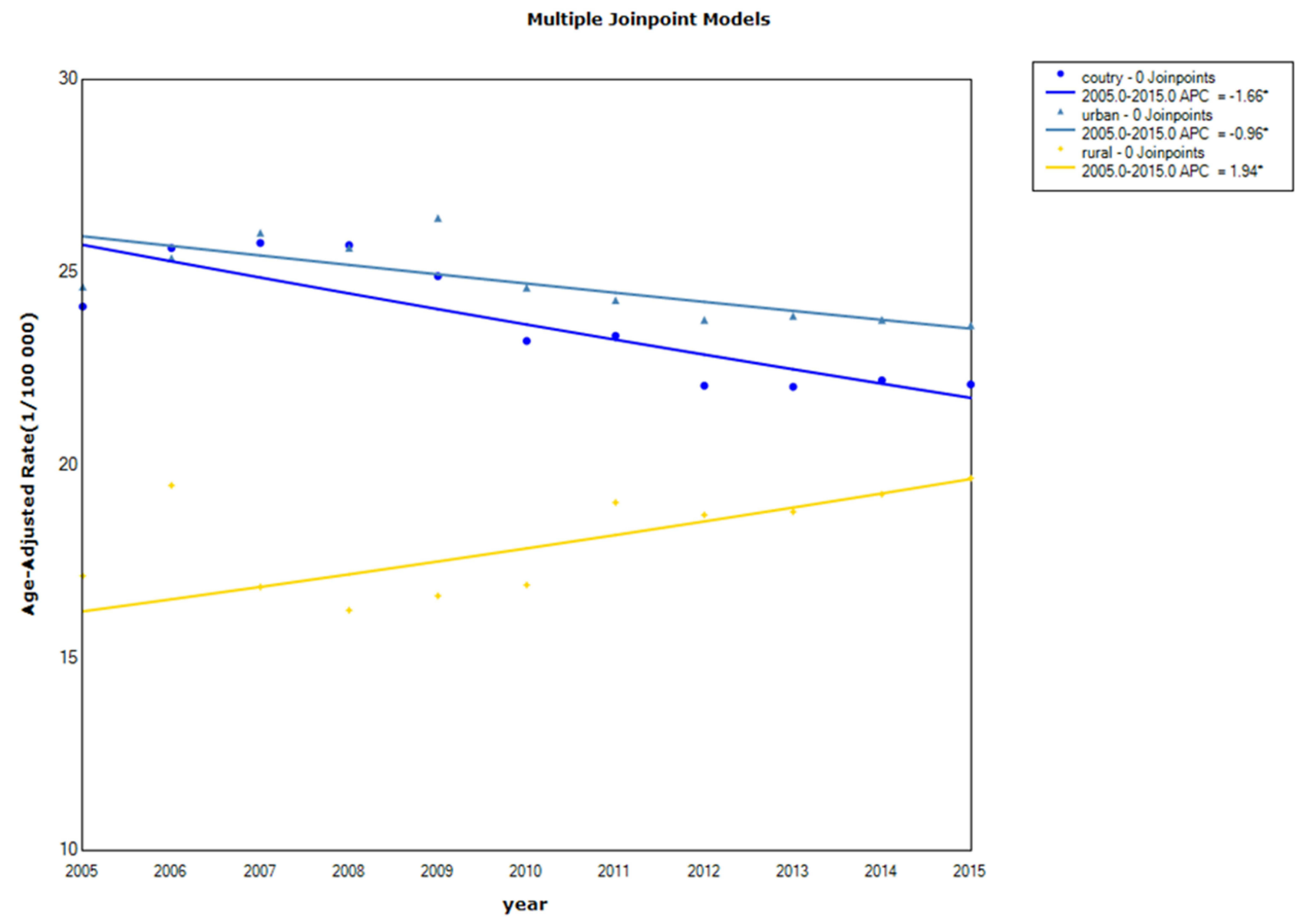

Figure 3 Trend of urban-rural standardized incidence of colorectal cancer in China from 2005 to 2015. Note: *Means $\mathrm{P}<0.05$, and the difference is statistically significant.

mortality, the trend can be divided into $2-3$ sections. In 2005 and 2007, the mortality of age group 0-59 showed a slow upward trend, and the group 60 had a rapid increase. There were three sections in other years: before the age of 45, the mortality increased slightly and smoothly; then increased gradually in the age group 45-65 and increased rapidly with the age after 65 .

\section{Risk Factors Analysis with Poisson Regression}

The risk factors of colorectal cancer incidence in China from 2005 to 2015 are shown in Table 3. The residual deviance and Pearson value was 60,475 and 53,569, respectively, and the degree of freedom was 787. Region, sex and age were independent risk factors for colorectal cancer incidence. In the same age group during the same period, the relative risk of colorectal cancer incidence in rural areas was 1.44 times that of urban areas (95\% CI: $1.432 \sim 1.450, \mathrm{P}<0.001)$, and men were 1.50 times that women $(95 \% \mathrm{CI}: 1.489 \sim 1.506, \mathrm{P}<0.001)$. For each additional 5 years of age, the incidence risk of colorectal cancer increased by $44 \%$ on average $(\mathrm{OR}=1.4,95 \% \mathrm{CI}$ : 1.439 1.44, $\mathrm{P}<0.001)$. The risk of incidence was reduced by an average of $0.06 \%$ each year, but the difference was not statistically significant $(\mathrm{OR}=1.0001, \mathrm{P}=0.3)$.

The risk factors of colorectal cancer mortality in China from 2005 to 2015 are shown in Table 4. The residual deviance and Pearson value were 31,773 and 37,739, respectively, and the degree of freedom was 787. Region, sex and age were independent risk factors for colorectal cancer death. In the same age group during the same period, the relative risk of colorectal cancer death in rural areas was 1.197 times that of urban areas (95\% CI: 1.187 1.27\%, $\mathrm{P}<0.001$ ), and men were 1.238 times that women (95\% CI: $1.228 \sim 1.248, \mathrm{P}<0.001$ ). For each additional 5 years of age, the death risk of colorectal cancer increased by $57 \%$ on average $(\mathrm{OR}=1.574,95 \% \mathrm{CI}$ : $1.572 \sim 1.577, \mathrm{P}<0.001)$. The risk of death increased by an average of $2.11 \%$ each year, and the difference was statistically significant $(\mathrm{OR}=1.02, \mathrm{P}<0.001)$. 
Multiple Joinpoint Models
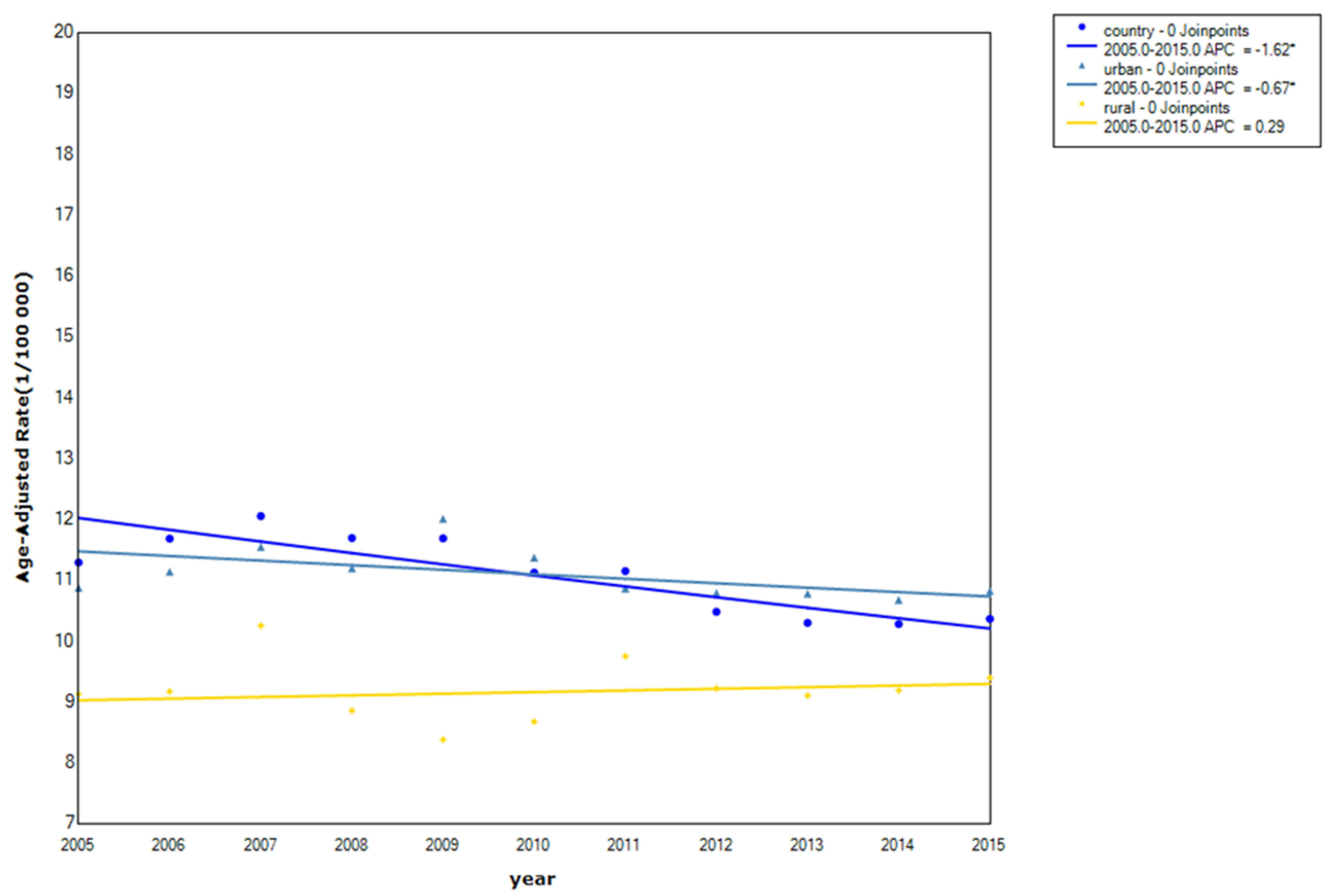

Figure 4 Trend of urban-rural standardized mortality of colorectal cancer in China from 2005 to 2015.

Note: *Means $\mathrm{P}<0.05$, and the difference is statistically significant.

\section{The Age-Period-Cohort Effect on Incidence and Mortality of CRC}

The result of the APC model is shown in Table 5. The age effect of colorectal cancer incidence and mortality risk increased with advancing age. Research on the incidence of CRC suggested that group aged 20-24 had the least risk of colorectal cancer, and the age effect coefficient is -2.49 . The risk of CRC was greatest in the 70-74 age group, and the age effect coefficient was 1.12. The period effect showed that incidence was statistically significant in

Table 2 APC and AAPC of Rural-Urban Standardized Incidence and Mortality of Colorectal Cancer in China from 2005 to 2015

\begin{tabular}{|l|c|c|c|c|c|c|c|}
\hline \multirow{2}{*}{ Areas } & \multirow{2}{*}{ Year } & \multicolumn{3}{|c|}{ Annual Change } & \multicolumn{3}{c|}{ Average Annual Change } \\
\cline { 3 - 8 } & & APC (95\% Cl) & $t$ & P & AAPC (95\% CI) & t & \\
\hline ASIR & & & & & & \\
All & $2005-2015$ & $-1.66^{*}(-2.33,-1.00)$ & -5.60 & 0.00 & $-1.66(-2.33,-1.00)$ & -5.60 & 0.00 \\
Urban & $2005-2015$ & $-0.97^{*}(-1.48,-0.45)$ & -4.19 & 0.00 & $-0.97 *(-1.48,-0.45)$ & -4.19 & 0.00 \\
Rural & $2005-2015$ & $1.94^{*}(0.99,2.90)$ & 4.63 & 0.00 & $1.94 *(0.99,2.90)$ & 4.63 & 0.00 \\
ASMR & & & & & & & \\
All & $2005-2015$ & $-1.62 *(-2.22,-1.02)$ & -6.09 & 0.00 & $-1.62 *(-2.22,-1.02)$ & -6.09 & 0.00 \\
Urban & $2005-2015$ & $-0.67^{*}(-1.30,-0.03)$ & -2.35 & 0.04 & $-0.67 *(-1.30,-0.03)$ & -2.35 & 0.04 \\
Rural & $2005-2015$ & $0.29(-0.76,1.36)$ & 0.63 & 0.54 & $0.29(-0.76,1.36)$ & 0.63 & 0.54 \\
\hline
\end{tabular}

Note: *Means $\mathrm{P}<0.05$, and the difference is statistically significant.

Abbreviations: ASIR, age-standardized incidence rate; ASMR, age-standardized mortality rate. 


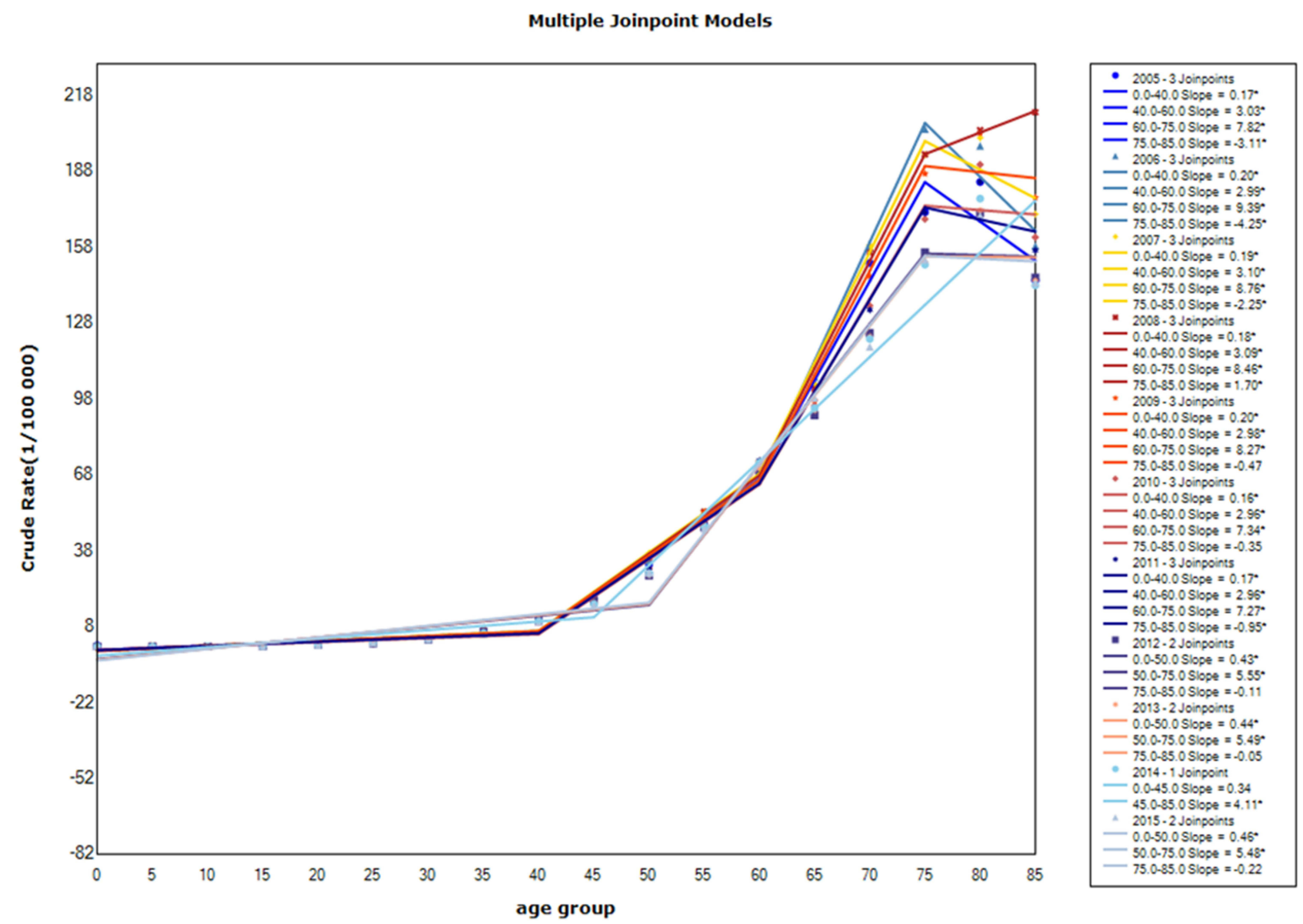

Figure 5 Trend of age-specific incidence of colorectal cancer in China from 2005 to 2015.

Note: *Means $\mathrm{P}<0.05$, and the difference is statistically significant.

2005 and 2015, mortality was statistically significant in 2005. The cohort effect showed that the birth cohort in 1920 had the greatest risk of CRC and the cohort effect coefficient was 1.34. The birth cohort in 1985 had the lowest risk of $\mathrm{CRC}$, and the cohort effect coefficient was -1.08 . The birth cohort in 1920 had the greatest death risk of CRC and the cohort effect coefficient was 1.60. People who were born in 1940 had the lowest risk of CRC and the cohort effect coefficient was 0.67 .

\section{Discussion}

This study showed that the standardized incidence and mortality trend of CRC in China was gradually decreasing during 2005-2015 but the burden was still serious. Specifically, men were higher than women, rural higher than urban, and the age-specific incidence and mortality tended to increase with age. We tried to compare the result with other studies and find out the possible reasons as follows.
To some extent, the decreasing trend was associated with the publishment of China Cancer Prevention and Control Program (2004-2010) ${ }^{15}$ issued by China's Ministry of Health, which declared early diagnosis and treatment as one of the main strategies of cancer prevention. In 2004, the Ministry of Health established 13 demonstration bases of cancer for early detection and treatment, covering 9 provinces. A series of programs of early diagnosis and treatment for cancer were launched successively in the Huaihe River Basin after that, which enhanced people's awareness of the risk factors and changing their lifestyles to prevent the occurrence of colorectal cancer.

In terms of gender, the incidence and mortality of both men and women were on the decline but women hit a turning point in 2013, then increased rapidly. However, men had a higher risk of CRC incidence and death than women all the time. The same gender difference was seen in previous study in China, ${ }^{16}$ Canada $^{17}$ and South Korea. ${ }^{18}$ Smoking, 


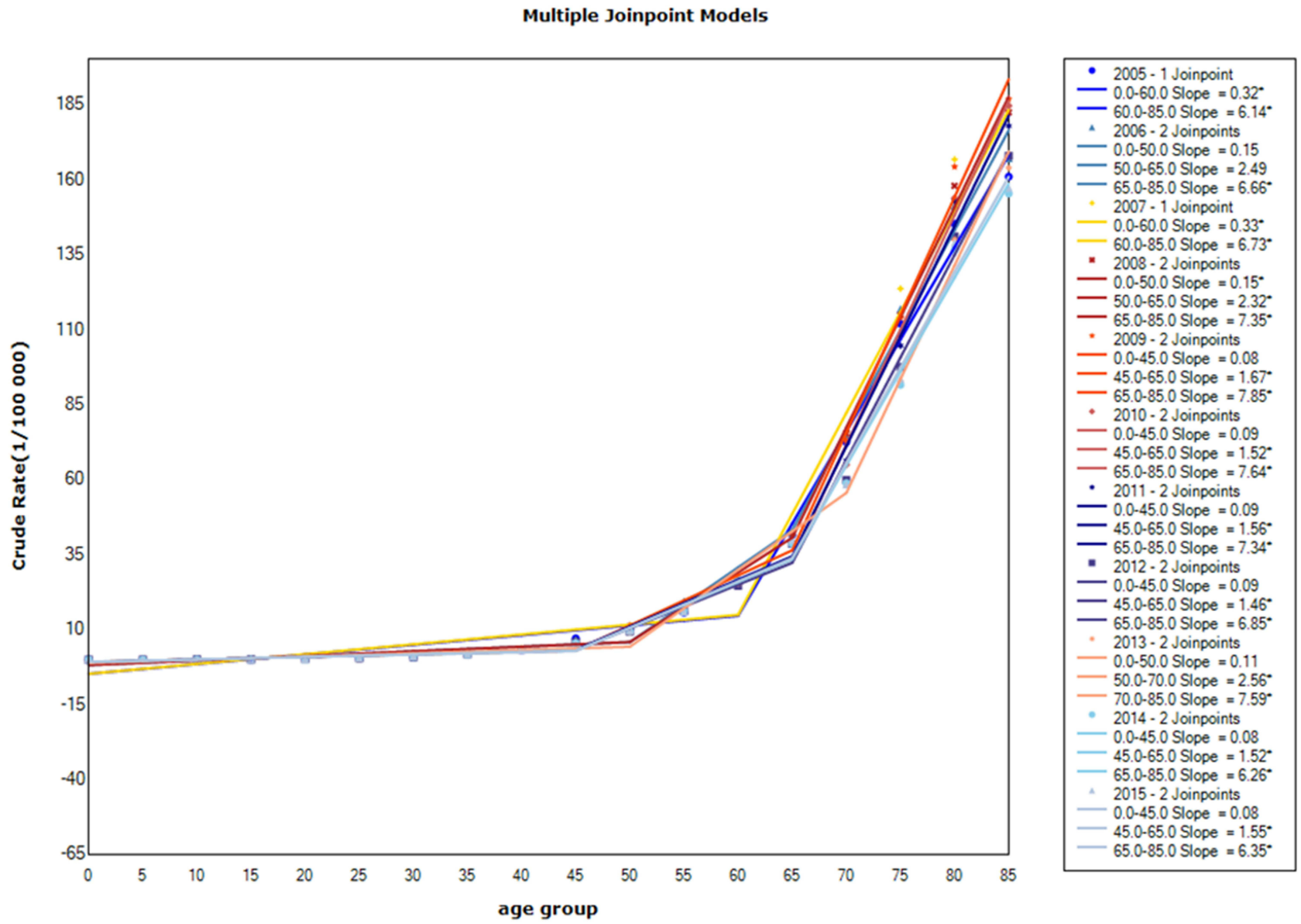

Figure 6 Trend of age-specific mortality of colorectal cancer in China from 2005 to 2015.

Note: *Means $\mathrm{P}<0.05$, and the difference is statistically significant.

obesity, alcohol drinking and physical inactivity appeared to be more relevant $\mathrm{CRC}$ contributor to men. ${ }^{15,18,19}$ Commonly, Chinese men smoke more frequently than women. ${ }^{20,21}$ Furthermore, research results ${ }^{19}$ showed that the transverse colon length of women was longer than that of men in colonoscopy, leading to a lower sensitivity to colorectal

Table 3 The Risk Factors in Colorectal Cancer Incidence in China from 2005-2015

\begin{tabular}{|c|c|c|c|}
\hline Factor & $\begin{array}{c}\text { Parameter Estimate } \\
(95 \% \mathrm{Cl})\end{array}$ & OR $(95 \% \mathrm{CI})$ & $P$ value \\
\hline Area & $0.365 \mid(0.3588,0.37 I 5)$ & $\begin{array}{c}\text { I.4407 (1.43 I7, } \\
\text { I.4499) }\end{array}$ & $P<0.001$ \\
\hline Gender & $0.4038(0.3979,0.4096)$ & $\begin{array}{c}\text { I.4974 (I.4886, } \\
\text { I.5062) }\end{array}$ & $P<0.001$ \\
\hline Age & $0.3648(0.3639,0.3657)$ & $\begin{array}{c}\mathrm{I} .4403(1.4390 \\
\mathrm{I} .4416)\end{array}$ & $P<0.001$ \\
\hline Year & $\begin{array}{c}0.0006(-0.0005 \\
-0.0016)\end{array}$ & $\begin{array}{c}\mathrm{I} .000 \mathrm{I}(0.995 \mathrm{I} \\
\mathrm{I} .0016)\end{array}$ & 0.3 \\
\hline
\end{tabular}

cancer screening in women. Due to the differences in biological and anatomical characteristics of colon between different genders, gender-specific endoscope devices with higher sensitivity need to be developed. Therefore, screening for female colorectal cancer should be the focus of monitoring and prevention of colorectal cancer in the future.
Table 4 The Risk Factors in Colorectal Cancer Mortality in China from 2005-2015

\begin{tabular}{|c|c|c|c|}
\hline Factor & $\begin{array}{c}\text { Parameter Estimate } \\
(95 \% \mathrm{Cl})\end{array}$ & OR $(95 \% \mathrm{Cl})$ & $P$ value \\
\hline Area & $0.1797(0.1712,0.1883)$ & $\begin{array}{c}1.1969(1.1867, \\
1.2072)\end{array}$ & $P<0.001$ \\
\hline Gender & $0.2135(0.2054,0.2216)$ & $\begin{array}{c}1.2380(1.228 \\
1.248 \mathrm{I})\end{array}$ & $P<0.001$ \\
\hline Age & $0.4538(0.4524,0.4552)$ & $\begin{array}{c}\text { I.5742 (I.5720 } \\
\text { I.5765) }\end{array}$ & $P<0.001$ \\
\hline Year & $0.0211(0.0196,0.0226)$ & $\begin{array}{c}1.0214(1.0198 \\
1.0229)\end{array}$ & $P<0.001$ \\
\hline
\end{tabular}


Table 5 Age-Period-Cohort (APC) Model Analysis Results of Colorectal Cancer Incidence and Mortality in China

\begin{tabular}{|c|c|c|c|c|c|c|}
\hline \multirow[t]{2}{*}{ Variables } & \multirow[b]{2}{*}{ Effect Coefficient } & \multirow[b]{2}{*}{ SE } & \multirow[b]{2}{*}{$\mathbf{Z}$} & \multirow[b]{2}{*}{$P$} & \multicolumn{2}{|c|}{$95 \% \mathrm{Cl}$} \\
\hline & & & & & LL & UL \\
\hline \multicolumn{7}{|c|}{ Age (incidence) } \\
\hline Age_20 & -2.49 & 0.85 & -2.92 & $0.00 *$ & -4.15 & -0.82 \\
\hline Age_25 & -1.75 & 0.50 & -3.50 & $0.00 *$ & -2.73 & -0.77 \\
\hline Age_30 & -1.17 & 0.38 & -3.09 & $0.00 *$ & -1.91 & -0.43 \\
\hline Age_35 & -0.80 & 0.34 & -2.34 & $0.02 *$ & -1.47 & -0.13 \\
\hline Age_40 & -0.37 & 0.31 & -1.22 & 0.22 & -0.97 & 0.23 \\
\hline Age_45 & -0.04 & 0.27 & -0.14 & 0.89 & -0.57 & 0.49 \\
\hline Age_50 & 0.34 & 0.23 & 1.49 & 0.14 & -0.11 & 0.78 \\
\hline Age_55 & 0.60 & 0.18 & 3.30 & $0.00 *$ & 0.24 & 0.96 \\
\hline Age_60 & 0.85 & 0.14 & 6.19 & $0.00 *$ & 0.58 & 1.12 \\
\hline Age_65 & 1.01 & 0.10 & 10.28 & $0.00 *$ & 0.82 & 1.21 \\
\hline Age_70 & 1.12 & 0.08 & 13.92 & $0.00^{*}$ & 0.96 & 1.28 \\
\hline Age_75 & 1.09 & 0.10 & 11.10 & $0.00 *$ & 0.89 & 1.28 \\
\hline Age_80 & 0.98 & 0.14 & 7.02 & $0.00 *$ & 0.70 & 1.25 \\
\hline Age_85 & 0.63 & 0.19 & 3.30 & $0.00 *$ & 0.26 & 1.01 \\
\hline \multicolumn{7}{|l|}{ Period } \\
\hline Period_2005 & -0.15 & 0.06 & -2.63 & $0.01 *$ & -0.27 & -0.04 \\
\hline Period_2010 & 0.02 & 0.03 & 0.65 & 0.51 & -0.04 & 0.07 \\
\hline Period_2015 & 0.14 & 0.06 & 2.36 & $0.02 *$ & 0.02 & 0.25 \\
\hline \multicolumn{7}{|l|}{ Cohort } \\
\hline Cohort_1920 & 1.34 & 0.24 & 5.61 & $0.00 *$ & 0.87 & 1.80 \\
\hline Cohort_1925 & 1.25 & 0.18 & 6.94 & $0.00 *$ & 0.90 & 1.61 \\
\hline Cohort_1930 & 1.07 & 0.14 & 7.89 & $0.00 *$ & 0.80 & 1.33 \\
\hline Cohort_1935 & 0.88 & 0.11 & 8.22 & $0.00 *$ & 0.67 & 1.09 \\
\hline Cohort_1940 & 0.63 & 0.11 & 5.91 & $0.00 *$ & 0.42 & 0.83 \\
\hline Cohort_1945 & 0.37 & 0.13 & 2.80 & $0.01 *$ & 0.11 & 0.63 \\
\hline Cohort_1950 & 0.26 & 0.17 & 1.54 & 0.12 & -0.07 & 0.60 \\
\hline Cohort_1955 & 0.14 & 0.22 & 0.64 & 0.52 & -0.28 & 0.56 \\
\hline Cohort_1960 & -0.06 & 0.26 & -0.22 & 0.83 & -0.57 & 0.45 \\
\hline Cohort_1965 & -0.28 & 0.30 & -0.92 & 0.36 & -0.87 & 0.31 \\
\hline Cohort_1970 & -0.47 & 0.34 & -1.39 & 0.16 & -1.14 & 0.19 \\
\hline Cohort_1975 & -0.63 & 0.37 & $-1.7 \mid$ & 0.09 & -1.34 & 0.09 \\
\hline Cohort_1980 & -0.92 & 0.40 & -2.28 & $0.02 *$ & $-1.7 \mid$ & -0.13 \\
\hline Cohort_1985 & -1.08 & 0.47 & -2.32 & $0.02 *$ & -1.99 & -0.17 \\
\hline Cohort_1990 & -1.12 & 0.69 & -1.63 & 0.10 & -2.47 & 0.23 \\
\hline Cohort_1995 & -1.37 & 1.48 & -0.93 & 0.35 & -4.27 & 1.52 \\
\hline \multicolumn{7}{|c|}{ Age (mortality) } \\
\hline Age_20 & -2.72 & 1.52 & -1.79 & 0.07 & -5.70 & 0.26 \\
\hline Age_25 & -1.97 & 0.89 & -2.20 & $0.03 *$ & -3.72 & -0.22 \\
\hline Age_30 & $-|.4|$ & 0.69 & -2.05 & $0.04 *$ & -2.76 & -0.06 \\
\hline Age_35 & -0.83 & 0.60 & -1.37 & 0.17 & -2.01 & 0.36 \\
\hline Age_40 & -0.49 & 0.55 & -0.89 & 0.37 & -1.57 & 0.59 \\
\hline Age_45 & -0.14 & 0.48 & -0.29 & 0.78 & -1.08 & 0.80 \\
\hline Age_50 & 0.15 & 0.40 & 0.38 & 0.70 & -0.64 & 0.94 \\
\hline Age_55 & 0.38 & 0.32 & 1.18 & 0.24 & -0.25 & 1.01 \\
\hline Age_60 & 0.71 & 0.24 & 3.00 & $0.00 *$ & 0.25 & 1.17 \\
\hline Age_65 & 0.94 & 0.16 & 5.73 & $0.00 *$ & 0.62 & 1.26 \\
\hline Age_70 & 1.17 & 0.13 & 9.20 & $0.00 *$ & 0.92 & 1.42 \\
\hline Age_75 & 1.37 & 0.16 & 8.51 & $0.00 *$ & 1.05 & 1.69 \\
\hline
\end{tabular}

(Continued) 
Table 5 (Continued).

\begin{tabular}{|c|c|c|c|c|c|c|}
\hline \multirow[t]{2}{*}{ Variables } & \multirow[b]{2}{*}{ Effect Coefficient } & \multirow[b]{2}{*}{ SE } & \multirow[b]{2}{*}{$\mathbf{z}$} & \multirow[b]{2}{*}{$P$} & \multicolumn{2}{|c|}{$95 \% \mathrm{Cl}$} \\
\hline & & & & & LL & UL \\
\hline Age_80 & $\mathrm{I} .44$ & 0.24 & 6.09 & $0.00 *$ & 0.98 & 1.91 \\
\hline Age_85 & 1.38 & 0.33 & 4.21 & $0.00 *$ & 0.74 & 2.02 \\
\hline \multicolumn{7}{|l|}{ Period } \\
\hline Period_2005 & -0.21 & 0.10 & -2.02 & $0.04 *$ & -0.41 & -0.01 \\
\hline Period_2010 & 0.04 & 0.04 & 1.01 & 0.31 & -0.03 & 0.10 \\
\hline Period_2015 & 0.17 & 0.10 & 1.69 & 0.09 & -0.03 & 0.37 \\
\hline \multicolumn{7}{|l|}{ Cohort } \\
\hline Cohort_1920 & 1.60 & 0.40 & 3.99 & $0.00 *$ & 0.81 & 2.38 \\
\hline Cohort_1925 & 1.46 & 0.31 & 4.78 & $0.00 *$ & 0.86 & 2.06 \\
\hline Cohort_1930 & 1.23 & 0.22 & 5.47 & $0.00 *$ & 0.79 & 1.66 \\
\hline Cohort_1935 & 0.99 & 0.17 & 5.92 & $0.00 *$ & 0.66 & 1.32 \\
\hline Cohort_1940 & 0.67 & 0.16 & 4.13 & $0.00 *$ & 0.35 & 0.99 \\
\hline Cohort_1945 & 0.40 & 0.21 & 1.90 & 0.06 & -0.01 & 0.82 \\
\hline Cohort_1950 & 0.25 & 0.29 & 0.86 & 0.39 & -0.32 & 0.81 \\
\hline Cohort_1955 & 0.08 & 0.37 & 0.20 & 0.84 & -0.65 & 0.80 \\
\hline Cohort_1960 & -0.10 & 0.45 & -0.21 & 0.83 & -0.99 & 0.79 \\
\hline Cohort_1965 & -0.43 & 0.53 & -0.81 & 0.42 & -1.48 & 0.62 \\
\hline Cohort_1970 & -0.65 & 0.60 & -1.09 & 0.28 & -1.83 & 0.52 \\
\hline Cohort_1975 & -0.87 & 0.66 & -1.33 & 0.19 & -2.15 & 0.42 \\
\hline Cohort_1980 & -1.06 & 0.71 & -1.50 & 0.14 & -2.46 & 0.33 \\
\hline Cohort_I985 & -1.09 & 0.81 & -1.34 & 0.18 & -2.68 & 0.51 \\
\hline Cohort_1990 & -1.25 & 1.23 & -1.01 & 0.31 & -3.65 & 1.16 \\
\hline Cohort_1995 & -1.23 & 2.43 & -0.51 & 0.61 & -5.99 & 3.52 \\
\hline
\end{tabular}

Notes: *Means $\mathrm{P}<0.05$, and the difference is statistically significant. Incidence: variance $=1.15 ; \mathrm{AIC}=6.49 ; \mathrm{BIC}=-43.74$. Mortality: variance $=1.05 ; \mathrm{AIC}=5.68 ; \mathrm{BIC}=-43.80$. Abbreviations: SE, standard error; LL, lower limit; UL, upper limit. AIC, Akaike Information Criterion; BIC, Bayesian Information Criterion.

The standardized incidence and mortality of colorectal cancer in urban areas of China were higher than rural areas, and the gap between urban and rural areas gradually narrowed. The disparity between urban and rural areas may be due to uneven distribution of medical resources. ${ }^{22}$ Most of the high-quality hospitals in China are located in urban areas, thus limited rural population could get suitable treatment for malignant tumors. At the same time, high treatment $\operatorname{costs}^{23}$ also reduce the possibility of rural patients to hospitals. In addition, the awareness of cancer screening in urban areas was stronger than that in rural areas because of the high economic and educational level. ${ }^{15}$ Therefore, it is easier to detect malignant tumors early, which might lead to higher detection rates in urban areas. Due to much sedentary work and less fiber intake instead of more daily activities like walking in rural populations, obesity and a high body mass index $(\mathrm{BMI})^{24}$ was associated with the higher risk of CRC. The World Health Organization also pointed out that high-fat diet and excessive intake of animal protein, especially red meat, ${ }^{25}$ were risk factors for colorectal cancer.

Few studies have applied the APC model to analyze CRC trend in China. With regard to age, there was no significant changes before the age 45 and the incidence and mortality remained stable and low. After that, both of them increased rapidly with age, which was consistent with relevant studies. $^{26,27}$ The APC model showed that age effect increased with age, and it was an independent risk factor. In particular, the incidence reached the summit at the age of 75 . Increasing age effect could also be seen in breast cancer, ${ }^{28}$ liver cancer, ${ }^{29}$ and cervical cancer. ${ }^{30}$ This might be because the elderly kept bad lifestyles for years, accumulated some basic diseases and paid less attention to their health. Comparing the period effects in 2005 and 2015, of which incidence was statistically significant, the risk of CRC incidence increased. This was inconsistent with the economical development and policy advancement. Cohort effects showed people born in 1920s had the highest risk of CRC 
risk. Poor health conditions and little consciousness of health could be the possible causes.

In order to effectively reduce the incidence and mortality of colorectal cancer in China, it is necessary to further develop and implement comprehensive prevention and control strategies. In primary prevention, the unknown risk factors or causes of colorectal cancer should be actively explored, and publicity and education should also be strengthened to advocate people to maintain good habits and behaviors in their daily life, such as eating more foods rich in dietary fiber, ${ }^{31}$ calcium $^{32}$ and vitamin $\mathrm{D},{ }^{33}$ actively engaging in physical exercise, especially the middle-aged and elderly people. In secondary prevention, we should actively improve the early screening system of colorectal cancer, popularize the knowledge of cancer screening, improve the awareness and the screening rate of colorectal cancer, especially the sensitivity of female colorectal cancer screening programs. Based on the results of this study, the screening should be started at the age of 45 years old in rural areas and 40 in developed areas. Colonoscopy screening is recommended as a routine checkup ${ }^{34}$ for people who need sedentary jobs because sitting is also an important risk factor for colorectal cancer. In tertiary prevention, improving the medical level of rural areas with insufficient medical resources, providing high-quality treatment conditions and exploring factors related to the prognosis of patients to improve the survival rate of patients were necessary.

This study cited data from the Annual Report of Chinese Cancer Registry Annual Report, which increased reliability and accuracy compared with data from Global Burden of Disease (GBD). In addition, it utilized a variety of statistical methods to analyse incidence, mortality trends and risk factors, of which validity can be assured. Certainly, the period 2005-2015 was a little short for trend analysis. However, the study can still provide scientific references for colorectal cancer prevention and control.

\section{Conclusion}

In summary, the ASIR and ASMR of CRC in China during 2005-2015 were decreasing. In addition, region, gender and age were independent risk factors for incidence and mortality of CRC. Specifically, men had a higher risk of colorectal cancer than women and urban areas higher than rural ones even though the disparity was shrinking. Therefore, a great concern on men, rural areas and people aged over 75 years old should be aroused to prevent colorectal cancer. Health education and promotion, good dietary and exercising habits, early diagnosis and detection will be great measures to control the disease.

\section{Abbreviations}

CRC, colorectal cancer; APC model, age-period-cohort model; APC, annual percentage change; AAPC, average annual percentage change; OR, odds ratio.

\section{Data Sharing Statement}

The data were extracted from the Chinese Cancer Registry Annual Report, annually published by the National Cancer Center of China, of which validity and authority can be ensured.

\section{Consent for Publication}

All authors consent to publication.

\section{Acknowledgments}

Thank Ms. Li Xiang and Ms. Xu Jieru for providing technical assistance.

\section{Author Contributions}

All authors made a significant contribution to the work reported, whether that is in the conception, study design, execution, acquisition of data, analysis and interpretation, or in all these areas; took part in drafting, revising or critically reviewing the article; gave final approval of the version to be published; have agreed on the journal to which the article has been submitted; and agree to be accountable for all aspects of the work.

\section{Funding}

The study was funded by the National Natural Science Foundation of China (grant NO. 81673107).

\section{Disclosure}

All authors declare no conflicts of interest.

\section{References}

1. Kong JC, $\mathrm{Su} \mathrm{WK}, \mathrm{Ng} \mathrm{CW}$, et al. Colorectal cancer in younger adults from a Bi-National Colorectal Cancer Audit registry. ANZ J Surg. 2021;91(3):367-374. doi:10.1111/ans.16250

2. Stoffel EM, Murphy CC. Epidemiology and mechanisms of the increasing incidence of colon and rectal cancers in young adults. Gastroenterology. 2020;158(2SI):341-353. doi:10.1053/j.gastro.2019.07.055

3. Bray F, Ferlay J, Soerjomataram I, Siegel RL, Torre LA, Jemal A. Global cancer statistics 2018: GLOBOCAN estimates of incidence and mortality worldwide for 36 cancers in 185 countries (vol 68, pg 394, 2018). CA Cancer J Clin. 2020;70(4):313. 
4. Deng Y. Rectal cancer in Asian vs. western countries: why the variation in incidence? Curr Treat Option Oncol. 2017;18(10):1-8.

5. Siegel RL, Miller KD, Jemal A. Cancer statistics, 2017. CA Cancer J Clin. 2017;67(1):7-30.

6. Chen W, Zheng R, Baade PD, et al. Cancer statistics in China, 2015. CA Cancer J Clin. 2016;66(2):115-132. doi:10.3322/caac.21338

7. Yu W, Jiang J, Xie L, et al. Mortality trends in colorectal cancer in China During 2000-2015: a joinpoint regression and age-period-cohort analysis. Prev Chronic Dis. 2018;15:E156. doi:10.5888/pcd15.180329

8. Erin K, Sarah VW, Gemma C, et al. Familial and non-familial risk factors associated with incidence of colorectal cancer in young and middle-aged persons in Western Australia. Cancer Epidemiol. 2019;62(C):101591.

9. Azeem S, Gillani SW, Siddiqui A, Jandrajupalli SB, Poh V, Sulaiman SA. Diet and colorectal cancer risk in Asia-a systematic review. Asian Pac J Cancer Prev. 2015;16(13):5389-5396. doi:10.7314/APJCP.2015.16.13.5389

10. Thanikachalam K, Khan G. Colorectal cancer and nutrition. Nutrients. 2019;11(1):164. doi:10.3390/nu11010164

11. Xiaoxue L, Chuanhua Y, Yongbo W, Yongyi B, Yu L, Zhi-Jiang Z. Trends in the incidence and mortality of diabetes in China from 1990 to 2017: a joinpoint and age-period-cohort analysis. Int J Environ Res Pub Health. 2019;16(1):158.

12. Chaurasia AR. Long-term trend in infant mortality in India: a joinpoint regression analysis for 1971-2018. Indian J Hum Dev. 2020;14(3):394-406. doi:10.1177/0973703020975044

13. Ekpenyong EJ, Emenike IC. Analysis of deaths in a Nigerian hospital: the case of Federal Medical Centre (FMC), Umuahia. Int $J A d v$ Stat Probab. 2015;3(1):64-71.

14. Sun Y, Wang Y, Li M, et al. Long-term trends of liver cancer mortality by gender in urban and rural areas in China: an age-periodcohort analysis. BMJ Open. 2018;8(2):e020490. doi:10.1136/bmjopen-2017-020490

15. Zhu J, Tan Z, Hollis-Hansen K, Zhang Y, Yu C, Li Y. Epidemiological trends in colorectal cancer in China: an ecological study. Digest Dis Sci. 2017;62(1):235-243. doi:10.1007/s10620-016-4362-4

16. Shuzheng L, Rongshou Z, Meng Z, Siwei Z, Xibin S, Wanqing C. Incidence and mortality of colorectal cancer in China, 2011. Chin J Cancer Res. 2015;27(01):22-28.

17. Gao RN, Neutel CI, Wai E. Gender differences in colorectal cancer incidence, mortality, hospitalizations and surgical procedures in Canada. J Public Health (Oxf). 2008;30(2):194-201. doi:10.1093/pubmed/fdn019

18. Khil H, Kim SM, Hong S, et al. Time trends of colorectal cancer incidence and associated lifestyle factors in South Korea. Sci Rep. 2021;11(1):2413. doi:10.1038/s41598-021-81877-2

19. Kim SE, Paik HY, Yoon H, Lee JE, Kim N, Sung MK. Sex- and gender-specific disparities in colorectal cancer risk. World J Gastroenterol. 2015;21(17):5167-5175. doi:10.3748/wjg.v21.i17.5167

20. Wang $\mathrm{M}, \mathrm{Xu} \mathrm{S}$, Liu $\mathrm{C}$, et al. Trends of smoking prevalence and implications for chronic diseases in China: an analysis of data from serial national cross-sectional surveys. Lancet. 2018;392:S75.

21. Wang M, Luo X, Xu S, et al. Trends in smoking prevalence and implication for chronic diseases in China: serial national cross-sectional surveys from 2003 to 2013. Lancet Respir Med. 2019;7(1):35-45. doi:10.1016/S2213-2600(18)30432-6

International Journal of General Medicine

\section{Publish your work in this journal}

The International Journal of General Medicine is an international, peer-reviewed open-access journal that focuses on general and internal medicine, pathogenesis, epidemiology, diagnosis, monitoring and treatment protocols. The journal is characterized by the rapid reporting of reviews, original research and clinical studies
22. Wen D, Zou W, Wen X, et al. Urban-rural disparity in colorectal cancer incidence and increasing trend in relation to socioeconomic development and urbanization in China. J Int Med Res. 2018;46 (10):4181-4196. doi:10.1177/0300060518791090

23. Shen L, Li Q, Wang W, et al. Treatment patterns and direct medical costs of metastatic colorectal cancer patients: a retrospective study of electronic medical records from urban China. J Med Econ. 2020;23 (5):456-463. doi:10.1080/13696998.2020.1717500

24. Recalde M, Davila-Batista V, Diaz Y, et al. Body mass index and waist circumference in relation to the risk of 26 types of cancer: a prospective cohort study of 3.5 million adults in Spain. BMC Med. 2021;19(1):10. doi:10.1186/s12916-020-01877-3

25. Saadati HM, Okhovat B, Khodamoradi F. Incidence and risk factors of colorectal cancer in the Iranian population: a systematic review. $J$ Gastrointest Cancer. 2021;52(2):414-421. doi:10.1007/s12029020-00574-x

26. Qin Z, Ke L, Guo-Zhen L, et al. Incidence trends and age distribution of colorectal cancer by subsite in Guangzhou, 2000-2011. Chin $J$ Cancer. 2015;34(08):358-364. doi:10.1186/s40880-015-0026-6

27. Milena I, Irena I. Colorectal cancer mortality trends in Serbia during 1991-2010: an age-period-cohort analysis and a joinpoint regression analysis. Chin J Cancer. 2016;35(10):518-527.

28. Mubarik S, Wang F, Malik SS, et al. A hierarchical age-period-cohort analysis of breast cancer mortality and disability adjusted life years (1990-2015) attributable to modified risk factors among Chinese women. Int $J$ Environ Res Public Health. 2020;17(4):1367. doi:10.3390/ijerph17041367

29. Zeng HM, Cao MM, Zheng RS, et al. [Trend analysis of age of diagnosis for liver cancer in cancer registry areas of China, 2000 2014]. Zhonghua yu Fang Yi Xue Za Zhi. 2018;52(6):573-578. Chinese. doi:10.3760/cma.j.issn.0253-9624.2018.06.004

30. Li X, Zheng R, Li X, et al. Trends of incidence rate and age at diagnosis for cervical cancer in China, from 2000 to 2014. Chin $J$ Cancer Res. 2017;29(6):477-486. doi:10.21147/j.issn.10009604.2017.06.02

31. Mondul AM, Weinstein SJ, Layne TM, Albanes D. Vitamin D and cancer risk and mortality: state of the science, gaps, and challenges. Epidemiol Rev. 2017;39(1):28-48. doi:10.1093/epirev/mxx005

32. Chandler PD, Buring JE, Manson JE, et al. Circulating vitamin $\mathrm{D}$ levels and risk of colorectal cancer in women. Cancer Prev Res (Phila). 2015;8(8):675-682. doi:10.1158/1940-6207.CAPR-14-0470

33. Keum N, Aune D, Greenwood DC, Ju W, Giovannucci EL. Calcium intake and colorectal cancer risk: dose-response meta-analysis of prospective observational studies. Int $J$ Cancer. 2014;135 (8):1940-1948. doi:10.1002/ijc. 28840

34. Shaukat A, Kaalby L, Baatrup G, et al. Effects of screening compliance on long-term reductions in all-cause and colorectal cancer mortality. Clin Gastroenterol Hepatol. 2021;19(5):967-975. doi:10.1016/j.cgh.2020.06.019 across all disease areas. The manuscript management system is completely online and includes a very quick and fair peer-review system, which is all easy to use. Visit http://www.dovepress.com/ testimonials.php to read real quotes from published authors. 